\title{
Lidar temperature series in the middle atmosphere as a reference data set - Part 1: Improved retrievals and a 20-year cross-validation of two co-located French lidars
}

\author{
Robin Wing ${ }^{1}$, Alain Hauchecorne ${ }^{1}$, Philippe Keckhut ${ }^{1}$, Sophie Godin-Beekmann ${ }^{1}$, Sergey Khaykin ${ }^{1}$, \\ Emily M. McCullough ${ }^{2}$, Jean-François Mariscal ${ }^{1}$, and Éric d'Almeida ${ }^{1}$ \\ ${ }^{1}$ LATMOS/IPSL, UVSQ Université Paris-Saclay, Sorbonne Université, CNRS, Guyancourt, France \\ ${ }^{2}$ Department of Physics and Atmospheric Science, Dalhousie University, Halifax, Canada
}

Correspondence: Robin Wing (robin.wing@latmos.ipsl.fr)

Received: 20 April 2018 - Discussion started: 2 May 2018

Revised: 26 September 2018 - Accepted: 27 September 2018 - Published: 10 October 2018

\begin{abstract}
The objective of this paper and its companion (Wing et al., 2018) is to show that ground-based lidar temperatures are a stable, accurate, and precise data set for use in validating satellite temperatures at high vertical resolution. Long-term lidar observations of the middle atmosphere have been conducted at the Observatoire de Haute-Provence $(\mathrm{OHP})$, located in southern France $\left(43.93^{\circ} \mathrm{N}, 5.71^{\circ} \mathrm{E}\right)$, since 1978. Making use of 20 years of high-quality co-located lidar measurements, we have shown that lidar temperatures calculated using the Rayleigh technique at $532 \mathrm{~nm}$ are statistically identical to lidar temperatures calculated from the non-absorbing $355 \mathrm{~nm}$ channel of a differential absorption lidar (DIAL) system. This result is of interest to members of the Network for the Detection of Atmospheric Composition Change (NDACC) ozone lidar community seeking to produce validated temperature products. Additionally, we have addressed previously published concerns of lidar-satellite relative warm bias in comparisons of upper-mesospheric and lower-thermospheric (UMLT) temperature profiles. We detail a data treatment algorithm which minimizes known errors due to data selection procedures, a priori choices, and initialization parameters inherent in the lidar retrieval. Our algorithm results in a median cooling of the lidar-calculated absolute temperature profile by $20 \mathrm{~K}$ at $90 \mathrm{~km}$ altitude with respect to the standard OHP NDACC lidar temperature algorithm. The confidence engendered by the long-term crossvalidation of two independent lidars and the improved lidar temperature data set is exploited in Wing et al. (2018) for use in multi-year satellite validations.
\end{abstract}

\section{Introduction}

Rayleigh lidar remote sounding of atmospheric density is an important tool for obtaining accurate, high-resolution measurements of the atmosphere in regions which are notoriously difficult to measure routinely or precisely. A key strength of this technique is the ability to retrieve an absolute temperature profile from a measured relative density profile with high spatio-temporal resolution, accuracy, and precision. This kind of measurement is exactly what is required to detect long-term middle-atmospheric temperature trends associated with global climate change and is of great value for routine satellite and model validation (Keckhut et al., 2004).

Comparisons of middle-atmospheric temperatures measured from satellites to those measured from lidars have all noted a relative warm bias in lidar temperatures above $70 \mathrm{~km}$. Several recent examples of lidar-satellite relative warm bias in the upper mesosphere can be found in the work of $\mathrm{Ku}$ mar et al. (2003) (5-10 K relative to HALOE); Sivakumar et al. (2011) (5-10 K relative to HALOE, 6-10 K relative to COSMIC/CHAMP, and $10-16 \mathrm{~K}$ relative to SABER (Sounding of the Atmosphere using Broadband Emission Radiometry)); Yue et al. (2014) (13 K at $75 \mathrm{~km}$ relative to SABER); García-Comas et al. (2014) (3-4 K at $60 \mathrm{~km}$ relative to SABER and MIPAS); Yue et al. (2014) $(13 \mathrm{~K}$ at $75 \mathrm{~km}$ relative to SABER); Dou et al. (2009) $(4 \mathrm{~K}$ at $60 \mathrm{~km}$ relative to SABER); Remsberg et al. (2008) $(5-10 \mathrm{~K}$ at $80 \mathrm{~km}$ relative to SABER); and Taori et al. (2012a, b) (25 K near $90 \mathrm{~km}$ relative to SABER). The bias is generally attributed to lidar "initialization uncertainty" and model a priori contribu- 
tions to the temperature retrieval, but no systematic attempts are made to fully establish this conclusion. These authors also explore the possible influences of tides, lidar-satellite co-incidence criteria, satellite vertical averaging kernels, and satellite temperature accuracy as possible contributing factors.

The work of this paper is to evaluate the suitability of lidars as a reference data set and to address the problem of systematic errors due to initialization of the lidar algorithm. The subsequent comparison of the improved lidar temperatures to satellite measurements is conducted in the companion paper (Wing et al., 2018).

This work follows three main goals: (i) the introduction of the long-term data set and the instrumental changes, (ii) treatment of this heterogeneous data set for use in the accompanying paper, and (iii) improvement of the temperature algorithm and reduction of the warm bias compared to satellite soundings. These goals cannot be completely separated from each other, but goal (i) is broadly addressed in Sects. 2.1-3.2 and 3.4; goal (ii) is addressed in Sects. 3.3 and 3.4 and again in Sects. 3.5-4; and goal (iii) is addressed in Sect. 5.

Section 2 of this paper describes the current experimental setup, the specifications of two Observatoire de HauteProvence (OHP) lidars, and the measurement cadence of two key NDACC (Network for the Detection of Atmospheric Composition Change) lidar systems.

Section 3 of this paper outlines techniques for minimizing the magnitude of the aforementioned lidar-satellite temperature bias by systematically detailing a rigorous procedure for the treatment and selection of raw lidar data and will propose improvements to the standard NDACC lidar temperature algorithm for the UMLT (upper mesosphere and lower thermosphere) region.

Section 4 of this paper gives the net results of the temperature modifications and system improvements in the Lidar Température et Aérosols (LTA) lidar at OHP.

Section 5 of this paper compares the lidar temperatures produced by an NDACC-certified temperature lidar at $532 \mathrm{~nm}$ with temperatures produced by the non-absorbing $355 \mathrm{~nm}$ line of a co-located NDACC-certified ozone DIAL (dIfferential absorption lidar) system. This comparison is conducted using a large database of two co-located lidar systems with the goal of providing confidence in the long-term stability of the lidar technique at both wavelengths. There are currently 10 certified temperature lidars, six of which are current in their data submission and have temperature profiles freely accessible online. Similarly, there are 12 certified stratospheric ozone DIAL systems, of which five systems are current with data submission and are available through the NDACC website. We hope that this work will encourage sites with outstanding data obligations to submit their measurements and for DIAL ozone sites to seek validation for their temperature data products for inclusion in the NDACC database (CPC Team, 2018). As an ancillary goal we will show that temperatures produced by the Rayleigh lidar tech- nique are accurate, precise, and stable over multiple decades and as such are the ideal type of measurement for use in future ground-based validation of satellite temperatures. The result of this demonstration will be used in the companion paper (Wing et al., 2018) as justification for validating satellite data with lidar temperatures.

\section{Instrumentation description}

\subsection{Rayleigh lidar}

The OHP Rayleigh-Mie-Raman lidar, LTA (Lidar Température et Aérosols), uses a seeded Nd:YAG to produce a $532 \mathrm{~nm}$ laser source with a maximum power of $24 \mathrm{~W}$. The transmitted beam is passed through a $13 \times$ beam expander and has a $30 \mathrm{~Hz}$ repetition rate, a $7 \mathrm{~ns}$ pulse width, and a beam divergence of less than $0.1 \mathrm{mrad}$.

The receiver assembly consists of a high- and low-gain elastic channel for $532 \mathrm{~nm}$, a Mie scatter channel at $532 \mathrm{~nm}$ for aerosols, a Raman channel at $607 \mathrm{~nm}$ for molecular nitrogen, and a Raman channel at $660 \mathrm{~nm}$ for water vapour. A schematic of the telescope array is shown in Fig. 1. The highgain Rayleigh channel consists of four telescopes. At the focal point of each telescope is an actuator-mounted $400 \mu \mathrm{m}$ diameter fibre optic. The four fibre optics are bundled to project a single signal onto a Hamamatsu R9880U-110 photomultiplier. The low-gain Rayleigh, nitrogen Raman, water vapour Raman, and Mie channels all use a single-telescope setup and actuator-mounted fibre optic. The two Raman channels rely on the largest telescope, and the signals are separated by a dichroic mirror. Specifications for each telescope are found in Table 1.

All channels are sampled using a Licel digital transient recorder with a record time of $0.1 \mu \mathrm{s}$, which corresponds to a vertical resolution of $15 \mathrm{~m}$. The high- and low-gain Raleigh channels are electronically gated at 22 and $12 \mathrm{~km}$, respectively, to avoid damaging the photomultipliers with large signal returns. Further details can be found in Keckhut et al. (1993) and Khaykin et al. (2017).

\subsection{DIAL ozone system $\left(\mathrm{LiO}_{3} \mathrm{~S}\right)$}

The OHP differential absorption lidar (DIAL), also referred to as Lidar Ozone Stratosphère $\left(\mathrm{LiO}_{3} \mathrm{~S}\right)$, uses two lasers to make a measurement of the vertical ozone profile using the differential absorption by ozone at two different wavelengths. The first laser is an $\mathrm{XeCl}$ excimer laser used to produce a $308 \mathrm{~nm}$ laser source with a maximum power of $10 \mathrm{~W}$. The beam is passed through a $3 \times$ beam expander and has a final divergence of less than $0.1 \mathrm{mrad}$. The second laser is a tripled Nd:YAG which is used to produce a $355 \mathrm{~nm}$ laser source with a maximum power of $2.5 \mathrm{~W}$. The beam is passed through a $2.5 \times$ beam expander and has a final divergence of less than $0.2 \mathrm{mrad}$. Both transmitted beams have a repetition rate of $50 \mathrm{~Hz}$ and a $7 \mathrm{~ns}$ pulse width. 
Table 1. Specifications for the LTA receiver assembly.

\begin{tabular}{lrrrrrr}
\hline LTA & $\begin{array}{r}\text { Mirror } \\
\text { diameter }(\mathrm{cm})\end{array}$ & $\begin{array}{r}\text { Focal } \\
\text { length }(\mathrm{mm})\end{array}$ & $\begin{array}{r}\text { Field of } \\
\text { view }(\mathrm{mrad})\end{array}$ & $\begin{array}{r}\text { Parallax } \\
(\mathrm{mm})\end{array}$ & $\begin{array}{r}\text { Optical filter } \\
\text { width }(\mathrm{nm})\end{array}$ & $\begin{array}{r}\text { Filter maximum } \\
\text { transmission }(\%)\end{array}$ \\
\hline High-gain Rayleigh & $4 \times 50$ & 1500 & 0.27 & 800 & 0.3 & 84 \\
Low-gain Rayleigh & 20 & $600-800$ & 1.7 & 257 & 0.3 & 84 \\
Nitrogen Raman & 80 & 2400 & 0.6 & 600 & 1 & $\sim 50$ \\
Water Raman & 80 & 2400 & 0.6 & 600 & 1 & $\sim 50$ \\
Aerosol Mie & 20 & $600-800$ & 1.7 & 257 & 0.3 & 84 \\
\hline
\end{tabular}

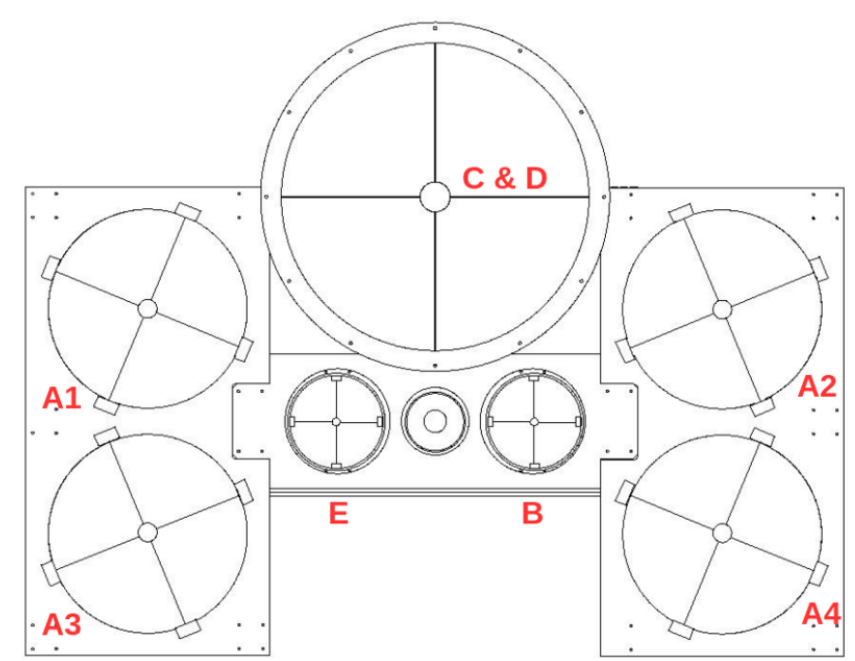

Figure 1. Mirrors A1, A2, A3, and A4 $(50 \mathrm{~cm})$ are combined for the high-gain Rayleigh channel. B $(20 \mathrm{~cm})$ is the low-gain Rayleigh channel. Mirror C\&D $(80 \mathrm{~cm})$ is the Raman channel for water vapour and molecular nitrogen. $\mathrm{E}(20 \mathrm{~cm})$ is the Mie channel. The beam expander for the transmitted laser source is between mirrors $\mathrm{E}$ and $\mathrm{B}$.

The receiver assembly consists of four $53 \mathrm{~cm}$ mirrors, each having a focal length of $1500 \mathrm{~mm}$, a field of view of $0.67 \mathrm{mrad}$, and an average parallax of $3100 \mathrm{~mm}$. Each of these four telescopes is focused onto an actuator-mounted $1 \mathrm{~mm}$ diameter fibre optic. The outgoing signals are bundled before being passed through a mechanical signal chopper to block low altitude returns below $8 \mathrm{~km}$, which would saturate the photon-counting electronics. The combined signal is split using a Horiba Jobin Yvon holographic grating with 3600 grooves $\mathrm{mm}^{-1}$ and a dispersion of $0.3 \mathrm{~mm} \mathrm{~nm}^{-1}$. The light from the grating is projected directly onto the photomultipliers for a high-gain (92\%) and low-gain (8\%) Rayleigh channel at $308 \mathrm{~nm}$, a high-gain $(92 \%)$ and low-gain $(8 \%)$ Rayleigh channel at $355 \mathrm{~nm}$, and two Raman channels at 331.8 and $386.7 \mathrm{~nm}$ for molecular nitrogen. The spectral resolution of the light incident on the photocathode is on the order of $1 \mathrm{~nm}$. Figure 2 shows a schematic of the OHP DIAL system.

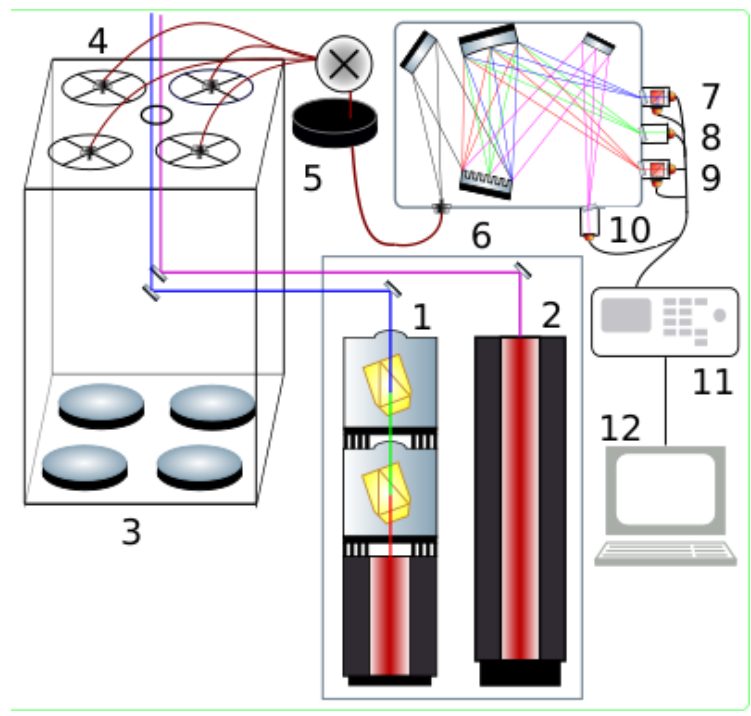

Figure 2. $\mathrm{LiO}_{3} \mathrm{~S}$ DIAL system. 1: $355 \mathrm{~nm}$ laser source; 2: $308 \mathrm{~nm}$ laser source; 3: four $530 \mathrm{~mm}$ mirrors; 4: four actuator-mounted fibre optic cables; 5: mechanical chopper; 6: Horiba Jobin Yvon holographic grating; 7: $308 \mathrm{~nm}$ high- and low-gain photomultipliers; 8: $331.8 \mathrm{~nm}$ photomultiplier; 9: $355 \mathrm{~nm}$ high- and low-gain photomultipliers; 10: $386.7 \mathrm{~nm}$ photomultiplier; 11: Licel transient signal recorder; 12: signal processing and analysis computer.

All channels are sampled using a Licel digital transient recorder with a record time of $0.25 \mu \mathrm{s}$, which corresponds to a vertical resolution of $75 \mathrm{~m}$. Further details can be found in (Godin-Beekmann et al., 2003).

\section{Methods}

In this section we will set forth rigorous and well-defined procedures for the retrieval of lidar temperatures in the middle atmosphere which will minimize the uncertainties at the upper limit of the lidar altitude range.

\subsection{Rayleigh lidar equation}

To calculate absolute temperature profiles from relative density profiles, we exploit the gradient of the measured profile of backscattered photons collected by the receiver. From 
classical lidar theory (Hauchecorne and Chanin, 1980), we know that the number of photons received is a simple product of transmitted laser power, atmospheric transmission, telescope geometry, and receiver efficiencies. This quantity can be expressed numerically in Eq. (1):

$$
\begin{aligned}
N(z) & =\xi_{\text {sys }} \cdot \tau_{\text {emitted }}(z, \lambda) \cdot \tau_{\text {return }}(z, \lambda) \cdot O(z) \cdot P_{\text {laser }} \cdot \frac{\lambda_{\text {laser }}}{h \cdot c} \\
& \cdot \sigma_{\text {cross }} \cdot n(z) \cdot \frac{A}{4 \pi z^{2}} \cdot \Delta t \cdot \Delta z+B .
\end{aligned}
$$

$N$ is the count rate of returned photons per time integration per altitude bin. $z$ is the altitude above the detector. $\xi_{\text {sys }}$ is the system specific receiver efficiency. $\tau_{\text {emitted }}(z, \lambda)$ is the transmittance of the photons through the atmosphere. $\tau_{\text {return }}(z, \lambda)$ is the return transmittance of the photons through the atmosphere. $O(z)$ is the overlap function of the receiver field of view. $P_{\text {laser }}$ is the laser power at a given wavelength. $\sigma_{\text {cross }}$ is the backscattering cross section of the target molecule. $n(z)$ is the number density of scatterers in the atmosphere. $\frac{A}{4 \pi z^{2}}$ is the effective area of the primary telescope. $\Delta t$ is the temporal integration for data collection. $\Delta z$ is the spatial range over which photons in a bin are integrated. $B$ is the background count rate.

There are four simple assumptions we make when Eq. (1) is used. First, we assume that each photon we count only scatters once. While this is almost certainly not the case, we can say that it is approximately true. Visual wavelength photons have a very low probability of scattering in the atmosphere, and with a multiple-scatter process we must square that very small probability. Of these multiply scattered photons, only those with a scatter angle towards the lidar receiver assembly will be seen, with the vast majority scattering outside of the field of view. Further, the tenuous nature of the UMLT means that the small probability of detecting a photon which has scattered more than once becomes exponentially negligible with increasing altitude.

Second, we assume that the atmospheric density is directly proportional to the number of returned photons incident on the receiver assembly. In the case of high signal returns from the lower atmosphere, when the number of returned photons can saturate the photon-counting electronics, the measured photon count rate will diverge from the received photon count rate. Multiple detection channels, at different sensitivities, are used to compensate for this effect. In this work we are primarily concerned with the UMLT, a region where lidars operate at very low count rates, so for the purposes of this work we can safely make this assumption. A correction for saturation in the lower stratosphere is described in Sect. 3.5.1.

Third, we assume that the atmosphere is in local hydrostatic equilibrium as well as local thermodynamic equilibrium (LTE) and obeys the ideal gas law. This assumption is potentially problematic at high altitudes where non-LTE processes can affect gravity wave dynamics and temperature profiles (Apruzese et al., 1984). However, given that a single lidar profile is acquired every $2.8 \mathrm{~min}$ and a nightly average temperature is generated every $4 \mathrm{~h}$, we can have some confidence in this assumption.

Fourth, we assume that the atmosphere at mid-latitudes is generally free of aerosols above $30 \mathrm{~km}$ when there are no active volcanic or fire events (Hauchecorne and Chanin, 1980). During less severe background aerosol conditions (aerosol scattering ratio < 1.02), Gross et al. (1997) suggest that lidar temperature cold biases due to Mie scattering are less than $0.5 \mathrm{~K}$ at $20 \mathrm{~km}$.

In the UMLT the signal-to-noise ratio (SNR) and the model-derived a priori assumptions for pressure and density are the main sources of error for the lidar temperature retrieval method. This paper lays out a rigorous method for reducing the noise in this region of the lidar signal with the goal of producing more robust mesospheric temperatures.

\subsection{The unprocessed lidar signal}

When backscattered photons are incident on the lidar receiver, they are integrated for a set period of time in the counting electronics. This ensures that the recorded signals are based on a similar number of transmitted photons. In the case of LTA a photon count profile, as a function of arrival time, is generated for every 5000 laser shots. Similarly for $\mathrm{LiO}_{3} \mathrm{~S}$ a photon counts profile is produced for every 8000 laser shots. These measurements can be further integrated for the entire night to increase the signal-to-noise ratio at the upper limit of the measurement range. We use the speed of light to convert our profiles of photon count rate per second as a function of arrival time at the detector to total photon count rate per second as a function of altitude.

Figure 3 shows four nightly integrated OHP lidar count rate profiles as a function of altitude. Both lidar systems employ a high-gain and a low-gain channel to extend the measurements over a greater altitude range. The lower altitudes (corresponding to the fastest signal return times) of each channel are either blocked by a mechanical chopper or electronically blanked. This is done to avoid saturation of the receiver assembly from very large signals in the lower atmosphere. Additionally, each channel has a set of optics designed to minimize the noise, with greater care being given to the high-gain channels. These optics are fully described in Sect. 2.

\subsection{Identifying outliers, signal spikes, signal-induced noise, and transient electronic interference}

When retrieving lidar temperature profiles in the UMLT, it is necessary to take extra precautions to carefully remove outliers, spikes, and electronic contamination from each profile in both the background region and the signal regions. Any contamination of the signal in the background region will be of the same order of magnitude as the true signal and, thus, 


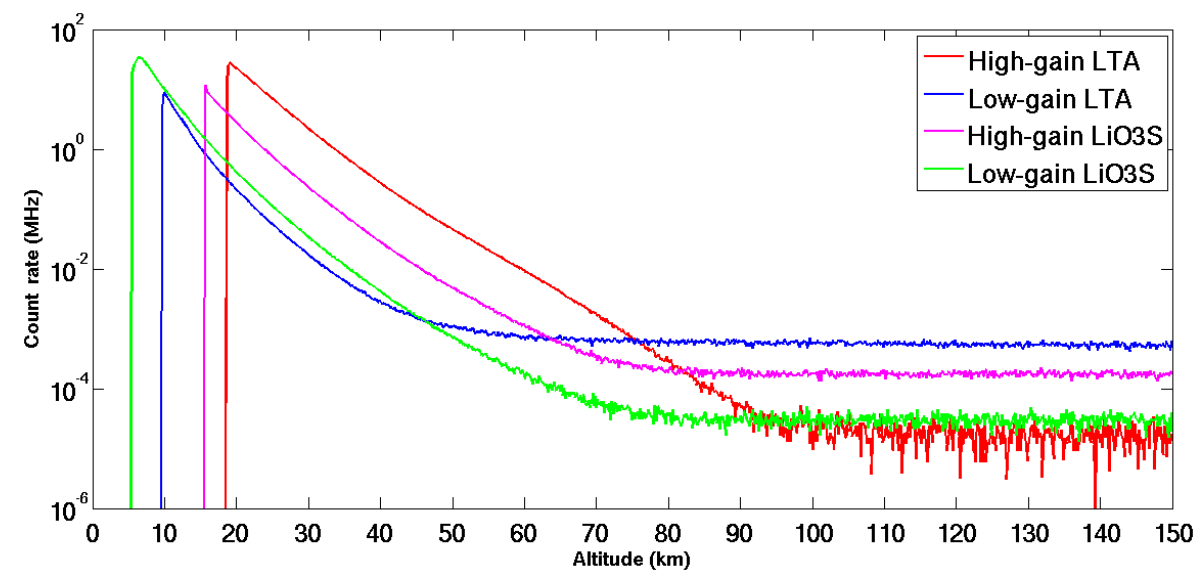

Figure 3. Nightly integrated profiles for high- and low-gain Rayleigh signals for LTA and $\mathrm{LiO}_{3} \mathrm{~S}$. The background for LTA extends to $246.23 \mathrm{~km}$ and for $\mathrm{LiO}_{3} \mathrm{~S}$ extends to $154.13 \mathrm{~km}$. A single lidar profile for both $\mathrm{LTA}$ and $\mathrm{LiO}_{3} \mathrm{~S}$ has a temporal resolution of roughly 2 min and $45 \mathrm{~s}$ and a vertical resolution of $75 \mathrm{~m}$.

have a disproportionate effect on the temperature. An overestimation of the background due to localized signal contaminations will result in the removal of true photons; a lower estimated density; and, by the ideal gas law, a higher temperature. The shape of the temperature profile itself will be distorted if there is a non-constant background. If it is not possible to fully correct the issue, it is highly recommended to exclude the entire profile from the nightly analysis.

\subsubsection{Spikes}

Spikes in fast-integration photon-counting data are not always easy to spot but can be defined as anomalously large, isolated signal rates which occur in only one altitude bin without affecting adjacent data. If not properly identified and extracted from the data, they can contribute to false temperature features and inaccurate background estimations. The spikes can have many potential origins (thermal or electronic imperfection in the photomultiplier, small charges in the Licel digital recorder, interaction of the photocathode substrate with a cosmic ray, or dozens of different kinds of electronic "cross-talk" between all the instruments at the observatory station) and are therefore impossible, in practical terms, to completely prevent in the lidar data set and completely impossible to prevent in measurements which have already been made. Therefore, it is necessary to address this problem using software during the analysis. It is particularly challenging to separate small-amplitude spikes when the signal-to-noise ratio approaches 1 . It is therefore necessary to establish a consistent criterion to determine which data points belong to the the population of real lidar returns and which points are likely contamination spikes. We have chosen to employ a straightforward Tukey quartile test (Tukey, 1949) on the difference between consecutively binned lidar returns as this statistic is relatively insensitive to signal drift during the course of the night. The quartile technique is equally useful in regions of high signal returns and in background regions, and it shows stability and consistency in identifying outliers. Figure 4 is a plot of photon count rate as a function of binned arrival time and shows an example of several photon count acquisitions plotted as a stack plot with the black line representing the $2 \sigma$ limit on the population of lidar returns. Data points above the black line are considered as signal contamination and are removed from the analysis.

\subsubsection{Transient electronic signals}

Transient electronic signals (TESs) are short-lived bursts in the lidar acquisition chain and may be internal to the system or related to nearby electronic interference. Possible sources for these transients include photomultiplier ringing from signal saturation, voltage fluctuations in the power supply, ambient radio frequency signals, and ground loops between lidar electronics and Ethernet switches with metal-sheathed cables. While these events are rare, they can drastically alter the background and resulting temperature profile by inducing wavelike structures into the data.

Unlike simple spikes, these features have an amplitude, a duration, and an effect on the counting rate in bins subsequent to the TES burst. In the example shown in Fig. 5 there is a surface plot of counts differences between consecutive altitude bins for the first 100 altitude bins of lidar data. Each bin is $0.1 \mu$ s wide. This plot shows profiles for a night of lidar data, with each profile accounting for roughly $1.6 \mathrm{~min}$ of lidar data. We can see that the 22nd and 46th profiles are contaminated by a TES with a duration of about $0.5 \mu \mathrm{s}$. These signals cannot be detected using the Tukey quartile test as the time derivative of the photon return signal may not be sufficiently far from the nightly population median. However, a 2-D kurtosis test will consistently detect this type of signal contamination as a TES will induce a large skew in the photon count rate population distribution. The kurtosis test is 


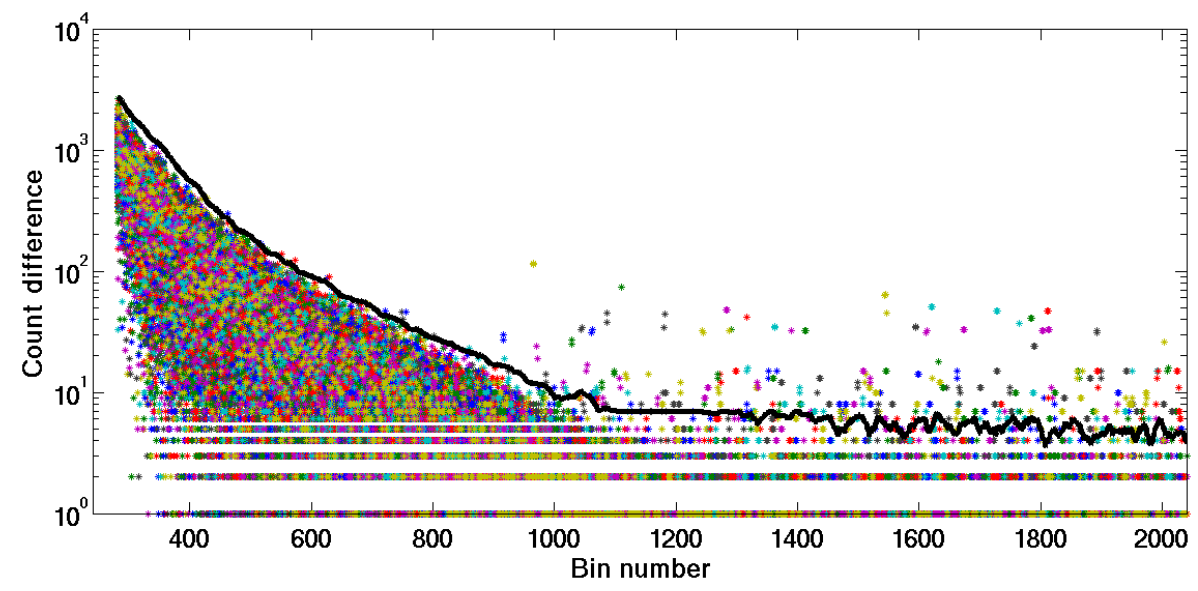

Figure 4. Tukey quartile spike identification based on the signal difference between consecutive lidar time bins for short integration lidar returns. An entire night of lidar profiles is over-plotted in the stack plot. The black line is the $2 \sigma$ limit, and points above this line are removed.

done in the time dimension as well as with altitude to exclude false positives in the photon count rate skew which may be due to clouds or aerosols. Figure 5 (bottom) shows a plot of the kurtosis in the population of photon counts in each lidar profile, and the red line shows the $2 \sigma$ estimation of total lidar profile skew. Isolated profiles with a total kurtosis above this limit are excluded.

\subsubsection{Bad profiles}

After the removal of lidar profiles which suffer from clear signal contamination, there may still be profiles which ought not be included in a lidar temperature analysis because they are outliers of poor quality compared to other profiles within the same night. Conceptually, "bad profiles" are lidar profiles with a high background and/or a low signal strength as compared to profiles measured shortly before or after the profile in question. These profiles need to be positively identified as not belonging to the general population of nightly lidar profiles. Quantitatively, identifying a bad profile is a challenge as both the background and the signal can change abruptly over the night as the laser power drops or sky conditions change (see Fig. 6 for an example). In the top panel of the figure we see the evolution of the background for a night of lidar data. We might suggest that profiles 1 through 23 and profiles 36 through 46 might belong to one population and the rest (excluding profile 69) belong to a second population. However, when we look at the panel representing the signal, it is equally reasonable to, instead, interpret the plot as containing four groups. Each of these groups has similar signals which match fairly well with the changes in the backgrounds shown in the panels above (profiles 1-23, profiles 24-35, profiles 36-48, and profiles 49-92). However, whether these four groups of signals should be treated in analysis as two, three, or four distinct populations is open to interpretation. Therefore, we seek an objective program- (a)

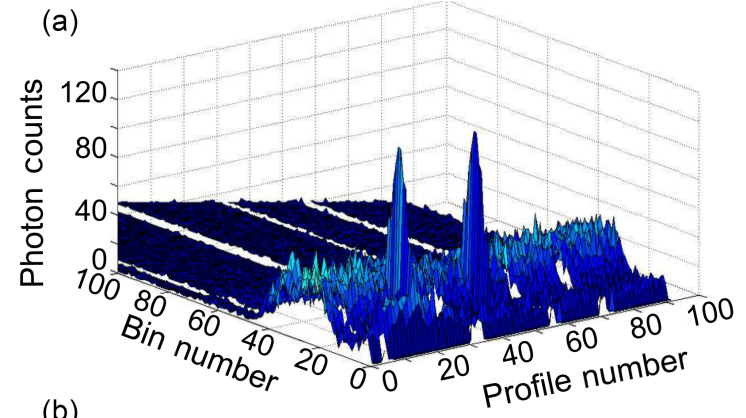

(b)

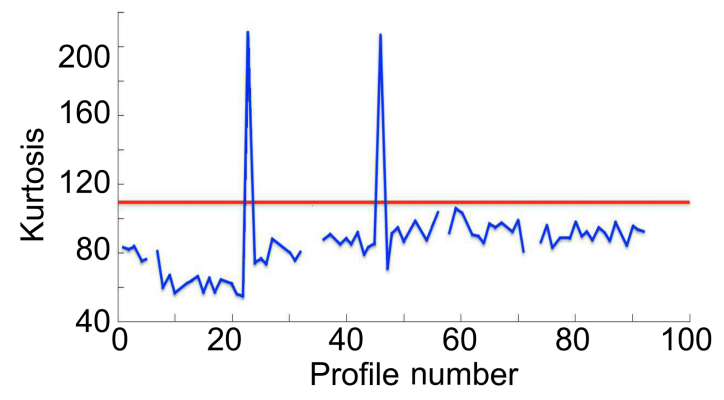

Figure 5. (a) is a surface plot of lidar returns as a function of time bin and profile number. For clarity, only the first 100 bins are shown in this plot. The test is carried out using all bins of each profile. Two instances of TES can be seen as anomalous peaks in the photon count rate. (b) is a summation of the fourth statistical moment (kurtosis/skew) for each scan. The red line indicates a $2 \sigma$ limit on the skew of the population. Points above the limit are excluded.

matic solution for identifying bad profiles. We now show two approaches for attempting to address the issue of changing signal quality. In Fig. 6 the green margin is an attempt to identify bad profiles based on a moving-average approach; however, this method cannot accommodate quick transitions 

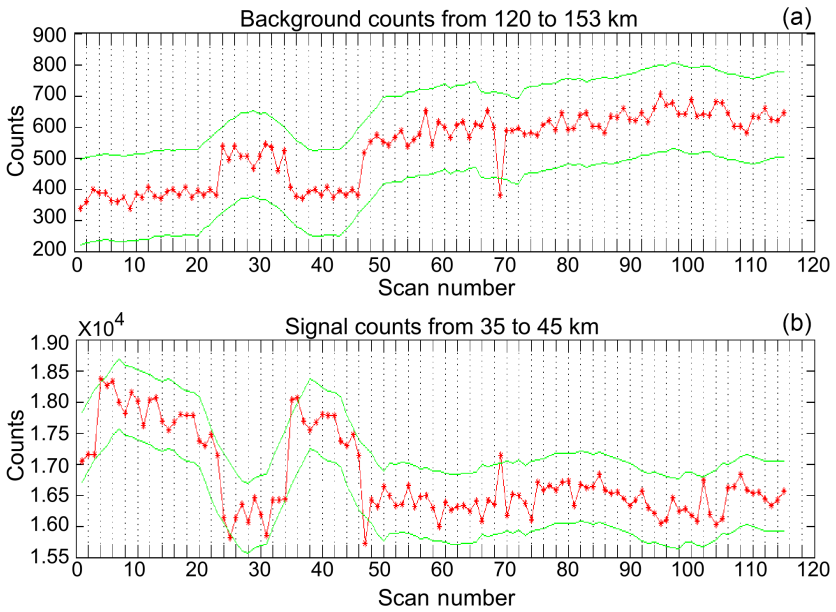

Figure 6. Example of lidar signal and noise during a night of measurements. (a) shows the total background counts summed from 120 to $153 \mathrm{~km}$, and (b) shows the total signal summed between 35 and $40 \mathrm{~km}$. Green bounds are calculated based on a smoothed $2 \sigma$ error estimation of the summed photon counts.

in signal strength and results in false positives when signal quality changes abruptly.

The simple reality of ground-based observation means that lidar signals clearly detect changes in the viewing conditions such as moonrise, thin cirrus clouds, optically thick clouds, changing light pollution, and changes in signal quality. Systematically identifying outlier signals is further complicated as there can be multiple signal-to-noise population medians during the course of the night. To properly characterize the non-Gaussian distribution of profiles and determine which should be excluded, we require a non-parametric statistic. We use a one-sided non-parametric Mann-Whitney-Wilcoxon rank-sum test (Mann and Whitney, 1947) to identify lidar profiles which do not belong to the nightly population or subpopulations of lidar profiles.

Figure 7 shows the ranked sum of the background (noise) and signal counts for a night of lidar data. We do not exclude the profiles which fail the test for having high quality. The benefit of using this metric is that it allows us to have a standardized definition of a bad profile which takes into account the nightly median without the assumption that the quality of lidar profiles is normally distributed. In this example the first 13 profiles fail the rank-sum test and are discarded.

\subsubsection{Good profiles}

Given that our objective is to calculate accurate temperature profiles at the highest possible altitudes, we must quality-test each profile that we choose to include in the nightly average. It is possible to include partial profiles, but that is not done in this work. The conceptual difference between a "bad profile" and a "good profile" is that bad profiles are positively identified as outliers to the general population whereas good
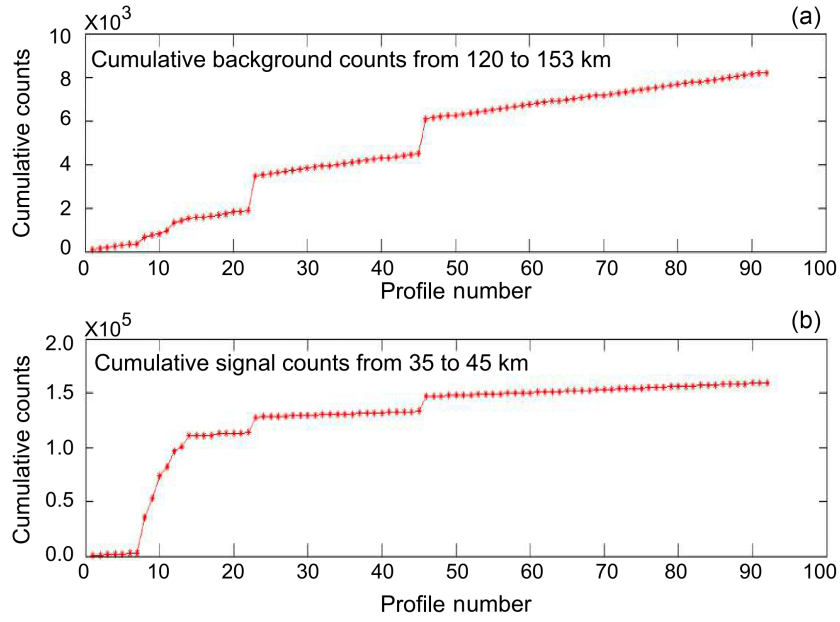

Figure 7. Rank-sum plots for a night of lidar data. (a) is the cumulative background count, and (b) is the cumulative signal count. The signal-to-noise ratio of the rank-summed photon counts in each profile is evaluated using a Mann-Whitney-Wilcoxon rank-sum test to determine if an individual lidar profile belongs to the nightly population of lidar profiles.

profiles represent the portion of the population of profiles which contribute more information than noise to the nightly average at a given altitude. Consider that a poor-quality lidar profile which has a signal-to-noise ratio of 1 at $70 \mathrm{~km}$ contributes more information from the signal than from the (background + noise) at $60 \mathrm{~km}$ but less information from the signal than from the (background + noise) at $80 \mathrm{~km}$. Thus, we need a flexible metric to determine signal quality over a diagnostic altitude which reflects the general signal quality of the night.

Quantitatively, we express this with a signal $(S)$-to-noise $(N)$ inequality in Eq. (2). The background (noise) of an individual profile, $N_{i}$, is expressed as the summation of photon counts in bins which fall between 120 and $155 \mathrm{~km}$, and the nightly background, $N_{\text {sum }}$, is the summation of all $N_{i}$ for the night. To determine a metric for the nightly average lidar signal, $S_{\text {sum }}$, we first calculate a quick density profile and determine the lowest altitude where the signal-to-noise ratio equals 1 . We chose a cutoff value of $\mathrm{SNR}=1$ because it is the least strict value we could use which ensures that we have more information than noise (or, specifically, more information than noise plus background counts) at the altitude within the density profile where we begin the downward temperature integration. Had we chosen a criterion which was less strict $(\mathrm{SNR} \ll 1)$, we would expect to see more statistical variability in the top altitudes of the temperature retrieval as a result of starting the temperature integration in a region which contains more noise than signal. Conversely, choosing a criterion which is too strict (SNR $\gg 1$ ) limits the maximum altitude of the temperature retrieval as discussed in Sect. 3.6.1. The SNR = 1 point forms the upper bound of the 
altitude range from which we derive the representative signal for the profile. The lower bound of this representative signal range is defined to be one density scale height $(\sim 8 \mathrm{~km})$ below the upper bound. The lidar range bins which correspond to this altitude range are then summed to yield $S_{\text {sum }}$. A similar calculation, using the same range bins as in the nightly average calculation, is done to determine the signal of a single profile, $S_{i}$. If a profile fails the inequality test, then it is not included in further nightly analysis.

$$
\sqrt{\frac{S_{\text {sum }}+N_{\text {sum }}}{S_{\text {sum }}}}<\sqrt{\frac{\left(S_{\text {sum }}-S_{i}\right)+\left(N_{\text {sum }}-N_{i}\right)}{S_{\text {sum }}-S_{i}}}
$$

\subsection{Noise reduction}

Statistical uncertainty in photon counting can be described by a Poisson distribution based on the square root of the number of photons received. Systematic uncertainties in the photon counts are introduced by ambient background light (light pollution, moonlight, etc.), thermal excitation in the photomultipliers (so-called dark current), and signal-induced noise. The first two sources of error are minimized by using narrow filters in the optical receiver chain and by cooling the photomultipliers. The signal-induced noise can be very difficult to correct experimentally and is usually estimated in data processing. This type of noise can occur if the photomultipliers have become saturated at any point in the signal acquisition process and often manifest as non-linear artifacts superimposed upon the true photon count profile.

Figure 8 shows the reduction in the background noise due to recent hardware improvements. The first drop corresponds to improvements made to the photomultiplier cooling system which reduces the number of thermally excited electrons detected at the photocathode of the photomultiplier in the absence of signal from the sky. The second drop in background counts results from replacing the Hamamatsu R7600U-20 multi-alkali photomultiplier with the improved Hamamatsu R9880U-110 photomultiplier having a super bialkali photo-cathode. The third and final drop in background counts is a result of replacing a $532 \mathrm{~nm}$ optical filter which has a width of $1 \mathrm{~nm}$ with a newer filter having a bandwidth of $0.3 \mathrm{~nm}$. These experimental modifications result in a 100fold decrease in the background noise and allow us greater confidence in our UMLT temperature retrievals. The regular monthly variations in the signal which become apparent at lower noise levels are due to the phase of the moon.

\subsection{Corrections applied before temperature calculation}

In the previous subsection we detailed the process for removing bad data points and profiles from our nightly lidar measurement. In this subsection we will detail several corrections to our remaining photon count profiles which correct for signal saturation, atmospheric transmission, and background estimation.

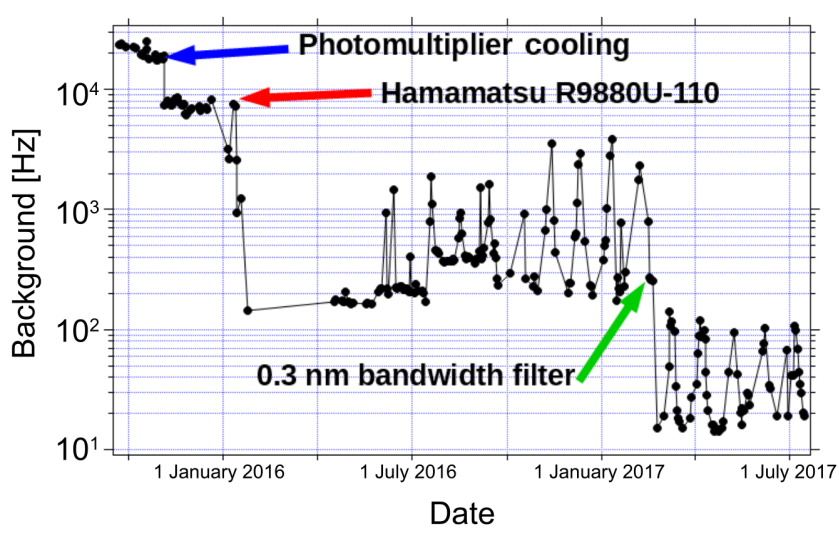

Figure 8. This figure shows the improvements in the background count rate due to photomultiplier cooling, new photomultipliers, and new optical filters. Note the logarithmic $y$ axis and the total reduction of background counts by more than 2 orders of magnitude.

\subsubsection{Dead-time correction}

The OHP lidars measure photons using photomultipliers and a digitizing signal counter. This system is highly efficient at detecting low signals and is optimized for single photon returns in the UMLT. However, given that the returned lidar signal directly follows the exponential density of the atmosphere, the photomultipliers and counting systems are susceptible to missing photons at lower altitudes due to high count rates. To correct for this saturation effect, we can estimate a correction coefficient, $\tau$, also referred to as a dead time.

The background theory and derivation of Eq. (3) is well described by Donovan et al. (1993), where $N_{\text {received }}$ is the number of photons incident on the photomultiplier tube per measurement time interval and $N_{\text {counted }}$ is the number of photons per measurement time interval which are actually counted by the system. In general, $N_{\text {counted }}<N_{\text {received }}$ due to effects of the system dead time. This dead-time correction can be calculated based on factory specification of the counting electronics or a theoretically derived dead time, or it can be measured directly using a low-gain lidar channel. The OHP lidars measure the dead time directly and correct for saturation in the high-gain channels with information from the low-gain channels. If the low-gain channel is not available, a theoretical correction of $7 \mathrm{~ns}$ is applied to pre-2013 data and $4 \mathrm{~ns}$ is applied to more recent data following the installation of a Licel digital recorder.

In order to measure the dead time experimentally, we assume that the low-gain channel, because it has low photon count rates, will always operate in the linear response regime and will never suffer from dead-time effects. Thus, it represents a value proportional to the "true" rate for returned photons for each altitude. Once it has been scaled by a constant (e.g. using MSIS (Mass Spectrometer and Incoherent Scat- 
ter Radar) or another model), we can use this count rate as $N_{\text {received }}$.

The high-gain channel, conversely, measures higher photon count rates at every altitude than the low-gain channel does. Similarly to the low-gain channel, at the low end of its dynamic range, the high-gain channel operates linearly and therefore represents a value proportional to the true rate for returned photons for each altitude. The constant of proportionality is different for low- and high-gain channels. At low count rates, the scaled counts measured by the high-gain and low-gain channels are equal. As photon count rates move into the higher end of the high-gain channel's dynamic range, dead time begins to have an effect: the high-gain channel will measure too few photons compared to the true rate the number of photons which are returned to the lidar. Therefore, we call the scaled high-gain count rate $N_{\text {uncorrected }}$ Eq. (3); it has not yet been dead-time-corrected. We will refer to the dead-time-corrected scaled high-gain count rate as $N_{\text {dtc }}$. Equation (3) is used several times. First, we use data only from altitudes for which the low-gain and high-gain channels both have measurements (nominally 40 to $60 \mathrm{~km}$ ). We iterate through various values of $\tau$, calculating a $N_{\mathrm{dtc}}$ for each $N_{\text {uncorrected value. This is carried out until the difference }}$ between $N_{\text {corrected }}$ (from the high-gain channel) and $N_{\text {received }}$ (from the low-gain channel) is minimized. This determines the dead time of the system, $\tau$. Next, Eq. (3) is used again, using the measured nightly value for $\tau$, to calculate $N_{\mathrm{dtc}}$ for all $N_{\text {uncorrected }}$ high-gain channel measurements. This allows us to correct the high-gain measurements for the entire profile.

$N_{\mathrm{dtc}}=N_{\text {uncorrected }} \times \exp \left(\frac{\tau \times N_{\text {uncorrected }}}{\Delta t}\right)$

\subsubsection{Atmospheric transmission correction}

To correct for Rayleigh extinction, we use the MSIS-90 model (Picone et al., 2002) to generate a vertical profile of ozone, molecular oxygen, oxygen radical, molecular nitrogen, and argon, and then apply the correct Rayleigh cross section to each species. This method is adapted from Argall (2007) and is important for accurate retrievals of density and neutral temperature in the UMLT. Correction for aerosols is not done in this work as we assume that the atmosphere is generally clean above $30 \mathrm{~km}$ (Hauchecorne and Chanin, 1980).

\subsubsection{Defining the background}

Normally, we assume that the rate of counted photons per laser shot is constant in the background region during the signal acquisition time and can therefore be approximated by a simple Poisson distribution. We further assume that in this background region we are not measuring returned photons from the laser signal but instead are measuring ambient sky light. However, if there is non-linear signal-induced noise in the photon-counting chain, the number of counted photons is not constant with time during the acquisition period of a single laser shot. When this occurs, we cannot assume that the variation in the background is a strictly Poisson distribution around a constant expected value.

If the number of true photons returned from the upper atmosphere is left uncorrected, we risk overestimating it, and the result is an artificially dense and cold UMLT. Erring on the side of caution, we fit three backgrounds (constant, linear, and quadratic) to each nightly summed profile in a standard diagnostic region and choose the function with the best chi-squared goodness of fit as our estimate of signal-induced noise. The best background function is subtracted from the raw photon counts profile. Shown in Fig. 9 is an example of a night where the low-gain Rayleigh channel (blue) experienced signal-induced noise which was best approximated by a quadratic function; the high-gain Rayleigh channel (red) had a background best estimated by a small negative linear function; and the nitrogen Raman channel (green) had no apparent signal-induced noise and was fit with a constant background. The optimal solution for non-linear signal-induced noise is to determine the contribution of both the signal and the noise using exponential fits; however, we have found that method to be extremely sensitive to the choice of background diagnostic region and less stable than the simple quadratic approximation.

We have some confidence that the quadratic background correction to the low-gain channel correctly approximates the moderate non-linear signal-induced error because we can compare the corrected low-gain channels to the high-gain channel. In the overlap region we have two channels making coincident measurements, and we can safely assume that the response rate for the high-gain channel is linear. Therefore, a correction for signal-induced noise in the low-gain channel which brings the resulting low-gain count rates into the closest agreement with the high-gain channel count rates at the same altitudes will be the optimal choice for the correction. In some cases, the quadratic correction for signalinduced noise in the low-gain channel yields better agreement than the constant or linear corrections, in which case it is employed. The best individual choice (constant, linear, quadratic) is used for each profile. We believe these empirical corrections to be sufficient, because (a) the resulting agreement with the high-gain channel improves as compared to the uncorrected profile; (b) the resulting corrected low-gain count profiles are generally equal to the high-gain count profiles to within statistical uncertainty; and (c) for the few cases in which the empirical correction ultimately fails, this will be apparent by the corrected signal retaining poor SNR values. The melding procedures of Sect. 3.6 weight the combined high- and low-gain Rayleigh channels according to SNR; so in these cases, the poorly corrected low-gain contributions to the final melded counts profile will be negligible, and all information will be obtained from the high-gain channel. 


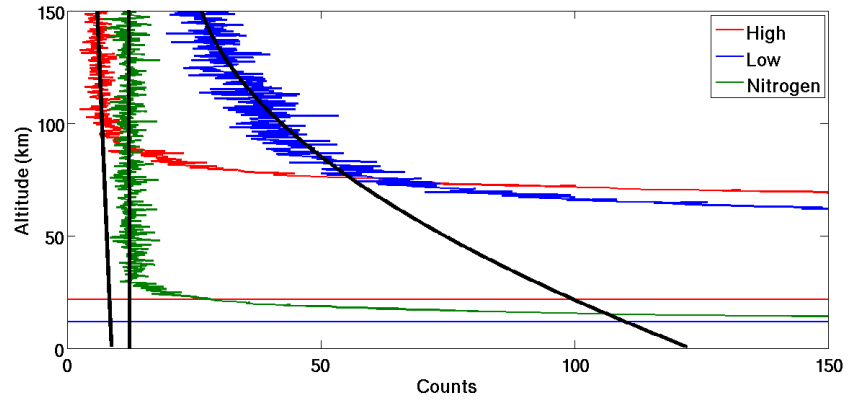

Figure 9. An example of non-linear signal-induced noise in the lowgain Rayleigh channel best estimated by a quadratic background. Also shown is the high-gain Rayleigh channel (red) with a background best fit by a negative linear function and the nitrogen Raman channel (green) with no apparent signal-induced noise and a constant background.

For the quadratic case, as soon as there is signal-induced noise, the profiles no longer represent Poisson distributions as the count rate in each lidar bin is no longer fully independent of the count rates in the bins on either side of it. Therefore, precise calculations of the SNR would require the addition in quadrature of real noise (from sky background and signal photon counts) and contamination noise (from signalinduced noise). Here, however, we make the assumption that the signal-induced noise is able to be completely removed from the raw profiles with the subtraction of the quadratic function. We therefore interpret the background-subtracted profiles to obey approximately Poisson distributions, thereby approximating the total noise in the profile to the noise of only the real photons, which can be treated as uncorrelated. Our standard altitude range for background selection is 120 to $155 \mathrm{~km}$, but this number is system and channel specific. To illustrate this point, we compare the background regions of the high-gain Rayleigh channel (red) and the nitrogen Raman channel (green) in Fig. 9. The nitrogen Raman channel background could be calculated from 50 to $155 \mathrm{~km}$ or 120 to $155 \mathrm{~km}$ and yield the same result.

\subsection{Temperature inversion equation}

The standard NDACC algorithm for Rayleigh temperature retrieval is the Hauchecorne-Chanin (HC) method (Hauchecorne and Chanin, 1980), which makes a scalar normalization of the photon count profile to an in situ density measurement or to a density calculated from a model like CIRA-72, SPARC-80, or MSIS-90. From a density gradient profile we calculate a pressure gradient profile, Eq. (4); using the ideal gas law, Eq. (5), we can arrive at an expression for pressure, Eq. (6). Here $P$ is pressure, $z$ is altitude above the lidar station, $\rho$ is density, $g$ is the latitude-dependent acceleration due to gravity for an ellipsoid Earth given by the Somigliana formula, $R$ is the ideal gas constant, $T$ is the temperature, and $M$ is the molecular mass.

$$
\begin{aligned}
& \mathrm{d} P(z)=-\rho(z) g(z) \mathrm{d} z \\
& P(z)=\frac{R \rho(z) T(z)}{M} \\
& \frac{\mathrm{d} P(z)}{P(z)}=-\frac{M g(z)}{R T(z)} \mathrm{d} z=\mathrm{d}(\log (P(z)))
\end{aligned}
$$

The crux of the challenge for initializing the lidar equation lies in the non-linear nature of Eq. (6), which will necessitate the introduction of an a priori estimate of pressure at the top of the atmosphere followed by an iterative approach to retrieving the profile at lower attitudes. A full theoretical description of this problem was well laid out by Khanna et al. (2012). In this work we have chosen to take our initial a priori seed pressure value, $P\left(z_{1}\right)$, from the MSIS-90 model. We now arrive at an iterative expression for the generation of the pressure profile as a function of altitude, Eq. (7).

$$
\frac{P\left(z_{i}\right)-\frac{\Delta z}{2}}{P\left(z_{i}\right)+\frac{\Delta z}{2}}=\exp \frac{M g\left(z_{i}\right)}{R T\left(z_{i}\right)} \Delta z
$$

Given our iteratively generated pressure profile, we can do an inverse calculation to map our pressures to a set of temperatures using Eqs. (8) and (9). This iteration starts at the top of the atmosphere, in a region of low signal-to-noise ratio and thus of large relative uncertainty, and proceeds downwards in altitude and becomes exponentially less uncertain with each step as signal quality improves with increasing atmospheric pressure. As we iterate downward, the influence of our choice of a priori pressure becomes less significant and the calculated temperature profile becomes entirely data driven.

$$
\begin{aligned}
& X_{i}=\frac{\rho\left(z_{i}\right) g\left(z_{i}\right) \Delta z}{P\left(z_{i}\right)+\frac{\Delta z}{2}} \\
& T\left(z_{i}\right)=\frac{M g\left(z_{i}\right)}{R \log \left(1+X_{i}\right)} \Delta z
\end{aligned}
$$

In order to calculate a single temperature profile from 5 to above $80 \mathrm{~km}$, we meld the photon counts from the high- and low-gain Rayleigh channels together with the counts from the $\mathrm{N}_{2}$ Raman channel. The slope of the logarithm of each of the three photon counts profiles is compared to a synthetic lidar counts profile generated based on the nightly average MSIS-90 density profile. The comparison gives us a first estimation of the linearity and alignment of the lidar data. We then select a clear linear region of each profile to use in calculating a MSIS derived scaling factor for each profile. This procedure allows the top of the nitrogen Raman profile to be melded to the bottom of the low-gain Rayleigh profile and the top of the low-gain Rayleigh profile to be melded to the bottom of the high-gain Rayleigh profile. The melding calculation is conducted over an altitude range defined by the 
signal-to-noise ratio and is a straightforward weighted average. The resulting melded density and pressure profiles are used to generate a single nightly average temperature profile like the one shown in Fig. 10. The use of MSIS-90 as a scalar density reference for the synthetic lidar profile does not affect the final lidar temperature profile, which depends only on the relative density and not the absolute value. We follow similar procedures to those described by Alpers et al. (2004).

\subsubsection{Where to start the inversion}

As can be seen in Eqs. (8) and (9), the calculation of lidar temperature requires an a priori guess of pressure at the top of the atmosphere and a relative density gradient. Given that the signal-to-noise ratio in the UMLT can be very low, the choice of a priori as well as the uncertainties in the density gradient can have a very large effect on the temperature profile (Khanna et al., 2011). As a result, it is prudent to remove the top $15 \mathrm{~km}$ of the retrieval to minimize the contribution of the a priori (Leblanc et al., 1998b).

In our treatment the a priori pressure is selected at the altitude where the signal-to-noise ratio in a smoothed photon counts profile is 1 . The resulting temperature profile is subsequently cut when the relative error exceeds $30 \%$. This treatment is not the optimal solution for the retrieval altitude as a fully Bayesian algorithm is required to properly characterize the influence of the a priori choice (Sica and Haefele, 2015). However, we believe that our signal-to-noise metric is sufficiently rigorous and, more importantly, reproducible.

\section{Net result of temperature algorithm modifications}

The NDACC algorithm contains such corrections as dead time, background, and transmission. The new algorithm improves upon the background correction and identification of bad profiles, and it introduces corrections for signal spikes, TES, identification of good profiles, and noise reduction, all of which have not previously been addressed by the NDACC algorithm.

The LTA data are recorded and saved at $75 \mathrm{~m}$ resolution. The spike and TES corrections described in Sect. 3.3.1 and 3.3.2 are carried out at this resolution. Then the profiles are integrated to $300 \mathrm{~m}$, at which point the remainder of the corrections in Sect. 3 are applied.

Temperature profiles using the new algorithm are calculated at $300 \mathrm{~m}$ resolution for LTA and are plotted as the green line in Fig. 11. This is higher resolution than the standard NDACC temperature resolution, which is $1 \mathrm{~km}$, smoothed to $2 \mathrm{~km}$ effective vertical resolution. The LTA NDACCcalculated temperatures (black line in Fig. 11) are plotted at $2 \mathrm{~km}$ effective resolution. By implementing the new algorithm, we have cooled the UMLT lidar temperature retrievals with respect to the standard NDACC temperature algorithm. The modifications cool the mesospheric retrievals by approx- imately $5 \mathrm{~K}$ near $85 \mathrm{~km}$ and $20 \mathrm{~K}$ by $90 \mathrm{~km}$. There is no significant difference between the new and the NDACC algorithms for LTA below $70 \mathrm{~km}$.

Temperature profiles calculated for $\mathrm{LiO}_{3} \mathrm{~S}$ are all carried out using the NDACC algorithm at an effective vertical resolution of $2 \mathrm{~km}$, and these are shown as the orange line in Fig. 11. Whereas the LTA NDACC algorithm results are warmer than the $\mathrm{LiO}_{3} \mathrm{~S}$ NDACC algorithm results above $70 \mathrm{~km}$, we now see that the new LTA algorithm results are cooled sufficiently that they more closely match the $\mathrm{LiO}_{3} \mathrm{~S}$ measurements up to $78 \mathrm{~km}$. Therefore the corrections for LTA proposed in the new algorithm represent a significant improvement over the LTA NDACC algorithm for altitudes above $70 \mathrm{~km}$.

A comparison with temperature retrievals from the satellites MLS (Microwave Limb Sounder, red line in Fig. 11) and SABER (blue with shaded ensemble variance), and with the MSIS-90 model (magenta line in Fig. 11), also shows an improvement in the LTA temperatures retrieved using the new algorithm as compared to the LTA NDACC algorithm. By implementing the techniques described in the sections above, we can account for nearly half of the temperature difference between the lidar and the satellites at $90 \mathrm{~km}$. The character change in the difference functions above and below $84 \mathrm{~km}$ is in part due to the increasing contributions of the speciesspecific Rayleigh backscattering correction and the corrections to the gravity vector. The remaining temperature difference between the improved lidar temperatures (green) and the satellites and model may be in part due to distortions in the satellite a priori for the geopotential vector. This possibility is explored further in the companion paper, and all coincidence criteria for the satellite comparisons are available therein (Wing et al., 2018).

It is important to note that additional complications exist when comparing temperatures derived from ground-based lidars to temperatures derived from satellite data which have their own calibration concerns. We explore the issues of lidar-satellite comparison in part 2 of this paper (Wing et al., 2018). A co-located ground-based resonance Doppler or Boltzmann lidar would provide a better comparison data set as resonance lidars have high signal-to-noise ratios above $75 \mathrm{~km}$ (Alpers et al., 2004).

\section{20-year comparison of OHP lidar temperatures}

Conducting systematic intercomparisons between independent lidar systems is essential for assuring data quality and is a requirement for NDACC-certified instruments. Most comparisons are conducted on a campaign basis where two or more lidar systems are co-located and make coincident measurements. A good example of this type of work was the stratospheric lidar and Upper Atmospheric Research Satellite (UARS) validation campaign (Singh et al., 1996). The present study proposes a completely novel type of inter-lidar 


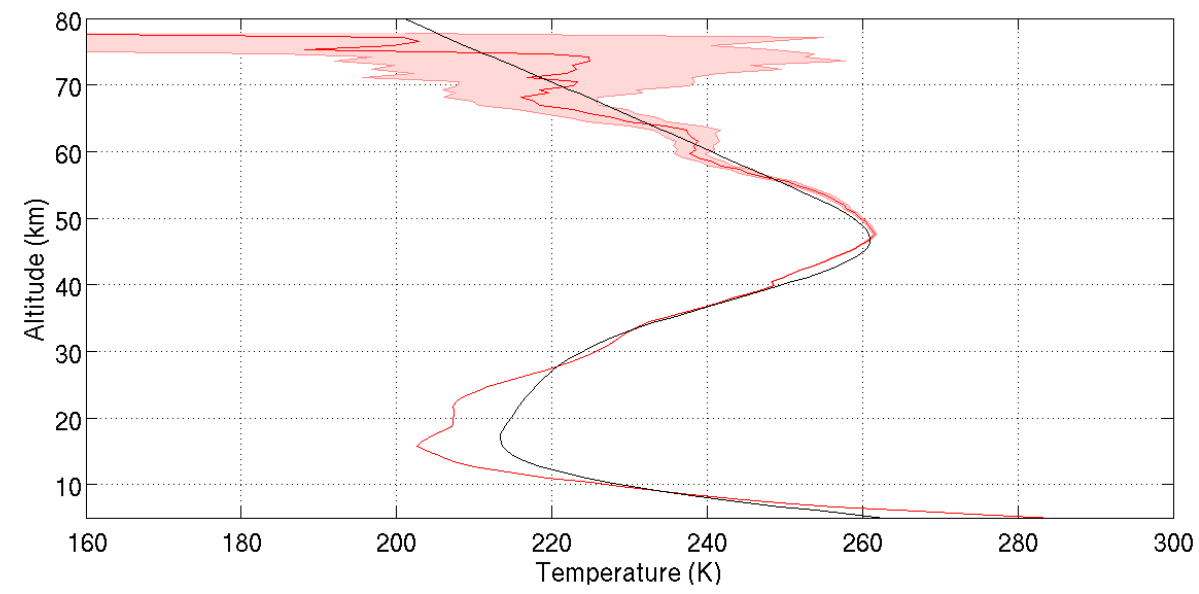

Figure 10. An example of a nightly average melded temperature profile from two Rayleigh channels and one Raman channel. The profile is calculated at $300 \mathrm{~m}$ vertical resolution from a single combined photon count profile and has a maximum relative error near $80 \mathrm{~km}$ of $30 \%$. Black line is the MSIS-90 temperature profile, which corresponds to the MSIS-90 pressure and density information we used as an a priori.

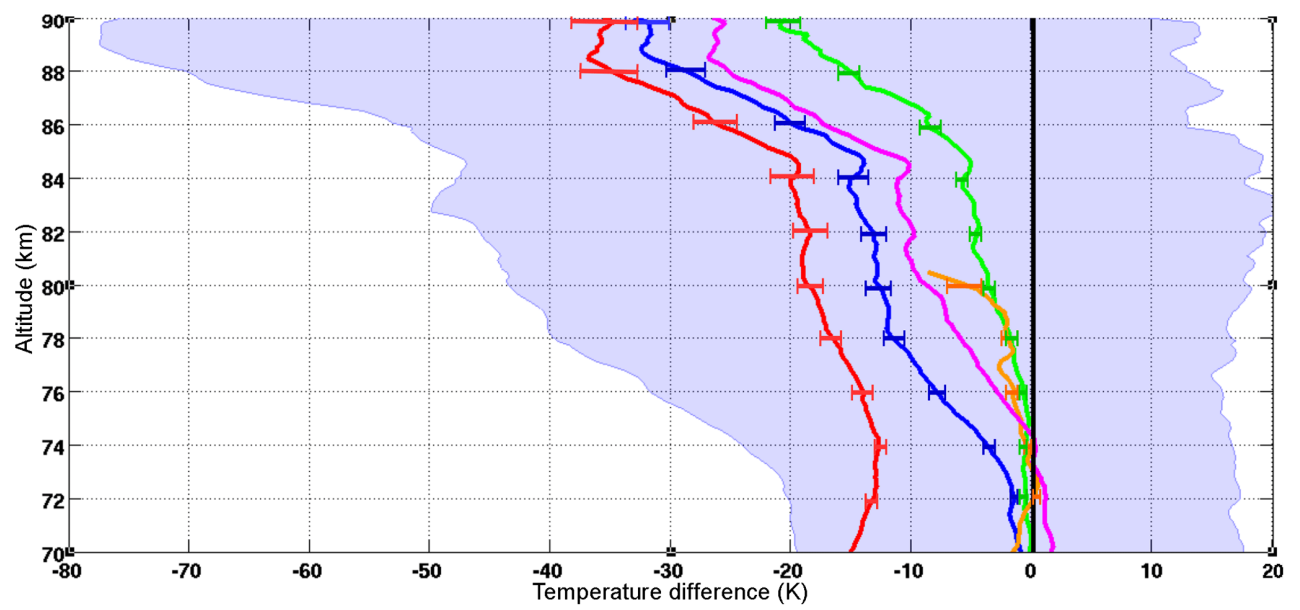

Figure 11. Ensemble temperature differences from NDACC standard LTA Rayleigh temperatures (black). MLS (red), SABER (blue with shaded ensemble variance), MSIS-90 (magenta), $\mathrm{LiO}_{3} \mathrm{~S}$ (orange), and LTA Rayleigh temperatures with corrections given in this work (green).

study on the long-term stability of the Rayleigh lidar technique. The first step in our analysis is to compare the temperature profiles from the LTA and $\mathrm{LiO}_{3} \mathrm{~S}$ systems. LTA temperatures were calculated using the OHP NDACC temperature code, and $\mathrm{LiO}_{3} \mathrm{~S}$ temperatures were calculated using a modified version of the same code. There are very few significant differences between these two codes. The most important difference involves the choice of parameters for melding the high- and low-gain channels for the two systems. Given the differences in the relative gain between the four lidar channels being considered, the melding of $\mathrm{LiO}_{3} \mathrm{~S}$ often occurs at a lower altitude than LTA. The present study considers temperatures between 35 and $75 \mathrm{~km}$ to ensure that we are well above any contamination from aerosols and below any significant initialization errors. From Fig. 11 we can see that there is no significant difference in the temperature outputs of these two algorithms (black baseline and orange) or with the improved algorithm (green) below $75 \mathrm{~km}$.

We selected the data from 1993 to 2013 for the comparison as both instruments operated regularly and without significant design changes during this time. Since the lidars are co-located and are operated by the same technicians, they often make measurements simultaneously. Figure 12 shows the average number of measurements per month made by the LTA and $\mathrm{LiO}_{3} \mathrm{~S}$ which were included in this study as well as the average number of common measurements per month. We defined common measurement times based on more than $80 \%$ temporal overlap, good-quality profiles in both systems, and good internal alignment of both lidars. Of the 2482 nights of LTA data and 3194 nights of $\mathrm{LiO}_{3} \mathrm{~S}$, 1496 nights met our criteria for coincidence. 


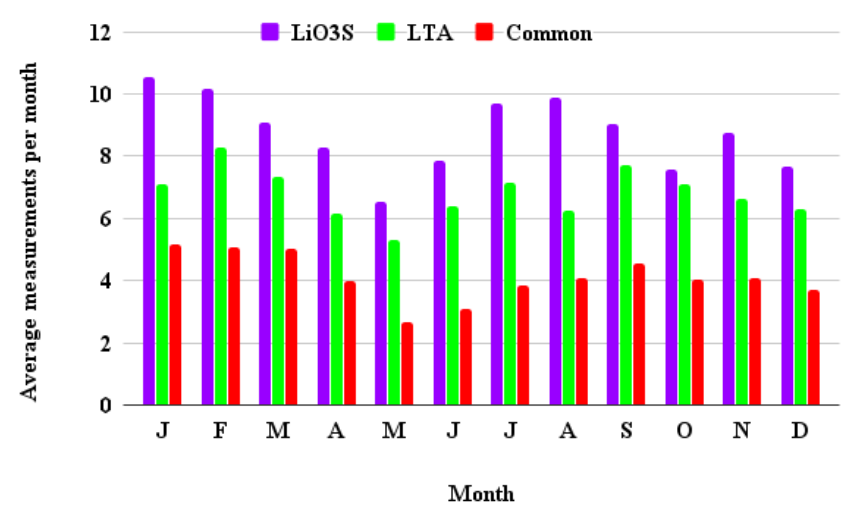

Figure 12. Average number of OHP lidar temperature measurements per month during the period of 1993-2013.

Figure 13 shows the nightly temperature differences between the two lidar systems. The 20-year data set contains 1496 coincident measurements lasting longer than $4 \mathrm{~h}$. Black vertical rectangles indicate some of the time periods where the high- or low-gain channels were misaligned in one or the other lidar. Internal misalignments happen when one or more of the five mirrors in LTA or four mirrors in LiO3S are not properly aligned with the laser or the fibre optic is not centred on the focal point of the mirror. A few of these time periods can be associated with minor system modifications. Misaligned lidar signals were identified by comparing the slopes of the density profiles in the high-gain (generally above $50 \mathrm{~km}$ ) and low-gain (below $\sim 50 \mathrm{~km}$ ) channels of each system. A simple chi-squared test was used to detect these nights and exclude them from the rest of the analysis. It is possible that the criteria described above for identifying periods of misalignment are not yet stringent enough. Therefore, one limitation of the OHP measurements in terms of accuracy, and depending on timescale as well as precision, is the influence of periods of misalignment that have not been programmatically identified. An ideal solution would be to have an independent method of monitoring mirror alignment during atmospheric measurements (e.g. installation of a small sighting telescope to measure the alignment coupled with an automatic fibre optic alignment system). With the existing data set from OHP extending back 2 decades, we unfortunately cannot retrospectively address such a hardware goal, but there may be opportunities in future to look into the effects of choosing different criteria to identify periods of misalignment.

Figure 14 shows four curves depicting the average temperature differences as a function of altitude and year. The red curve is the average temperature difference between 65 and $75 \mathrm{~km}$ with an average standard deviation of $6.6 \mathrm{~K}$; the green curve is the average temperature difference between 55 and $65 \mathrm{~km}$ with an average standard deviation of $4.5 \mathrm{~K}$; the blue curve is the average temperature difference between 45 and $55 \mathrm{~km}$ with an average standard deviation of $2.7 \mathrm{~K}$; and the magenta curve is the average temperature difference between 35 and $45 \mathrm{~km}$ with an average standard deviation of $1.6 \mathrm{~K}$. A 30-day averaging window is applied to each of the four curves.

For reference, a typical LTA temperature profile with an effective vertical resolution of $2 \mathrm{~km}$ has an uncertainty due to statistical error of $0.2 \mathrm{~K}$ at $40 \mathrm{~km} ; 0.4 \mathrm{~K}$ at $50 \mathrm{~km} ; 0.6 \mathrm{~K}$ at $60 \mathrm{~km} ; 0.7 \mathrm{~K}$ at $70 \mathrm{~km} ; 1.8 \mathrm{~K}$ at $80 \mathrm{~km}$; and $6 \mathrm{~K}$ at $90 \mathrm{~km}$. For reference, a typical LiO3S temperature profile with an effective vertical resolution of $2 \mathrm{~km}$ has an uncertainty due to statistical error of $0.3 \mathrm{~K}$ at $40 \mathrm{~km} ; 0.5 \mathrm{~K}$ at $50 \mathrm{~km} ; 1.0 \mathrm{~K}$ at $60 \mathrm{~km} ; 2.7 \mathrm{~K}$ at $70 \mathrm{~km}$; and $10 \mathrm{~K}$ at $80 \mathrm{~km}$.

Examining the time evolution of the average temperature differences between LTA and $\mathrm{LiO}_{3} \mathrm{~S}$ at four altitude levels gives us confidence that both measurements are stable in both time and altitude. When all data are used, including misaligned periods (example: winter 2006-2007 in Figs. 13 and 14), none of the lidar temperature differences are significant at the $2 \sigma$ level, although certain periods do have temperature differences which are detectable at the $1 \sigma$ level. This can be seen where the blue shaded region (2005-2008) and the magenta shaded region (in 2007) are entirely above the zero line. If the misaligned periods are disregarded, no temperature differences are significant, even at the $1 \sigma$ level. Therefore, we conclude that the results from the lidars, when well aligned, are stable in time, over the 20 -year period studied.

After removing comparisons between misaligned instruments, we can calculate the ensemble median difference between the two systems. The ensemble median difference in Fig. 15 shows very good agreement between the two colocated lidar instruments. The temperatures produced by LTA and $\mathrm{LiO}_{3} \mathrm{~S}$ are statistically equal above $45 \mathrm{~km}$ for the 20 -year period between 1993 and 2013. There is a small $-0.6 \mathrm{~K}$ systematic difference which reaches a maximum near $40 \mathrm{~km}$. We believe this slight cold bias is due to small differences in the signal melding technique between the high- and lowgain channels in both systems. On a typical night, the LTA low-gain channel starts to significantly contribute to the combined signal near $50 \mathrm{~km}$. If the photon count rate in the lowgain channel is too large at these altitudes (due to residual noise contributions or from a slight misalignment with the high channel), the counts will be artificially higher than expected, resulting in a lower temperature. The converse holds true when the low-gain channel is misaligned in the opposite sense, resulting in a slight warming due to underestimation of the counts.

The effect of these small temperature perturbations is so small that they cannot be seen in single nightly temperature comparisons and were not detected before this study. It is important to note that the $2 \sigma$ distribution about our ensemble at $40 \mathrm{~km}$ has a magnitude of approximately $0.45 \mathrm{~K}$ while the statistical error for a single night of lidar measurements near $40 \mathrm{~km}$ at $300 \mathrm{~m}$ vertical resolution can be on the order of $2 \mathrm{~K}$. Detecting and resolving this small disagreement will be 


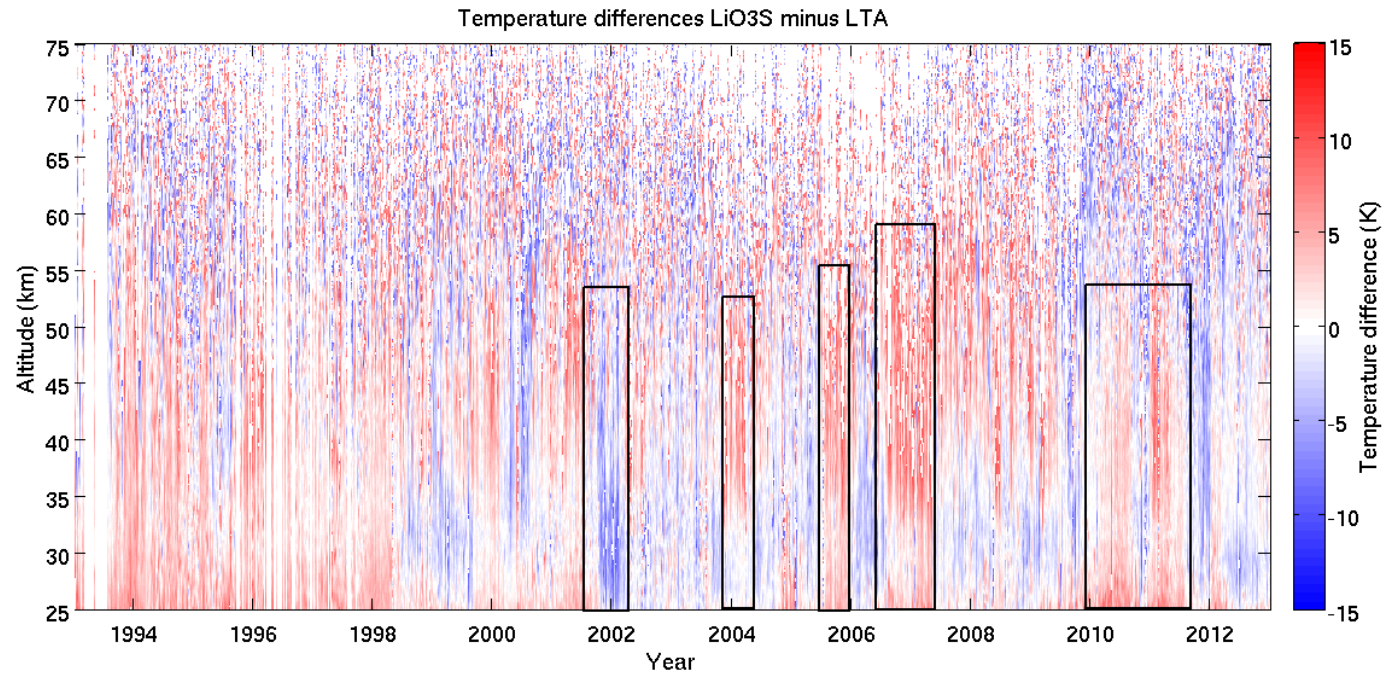

Figure 13. Temperature differences between LTA and $\mathrm{LiO}_{3} \mathrm{~S}$ OHP lidars for a 20-year period between 1993 and 2013 . There are 1496 nights of comparison in this plot. Red indicates that $\mathrm{LiO}_{3} \mathrm{~S}$ was warmer than LTA, and blue that it was colder. The black boxes highlight periods where the two lidars were out of alignment with respect to each other.

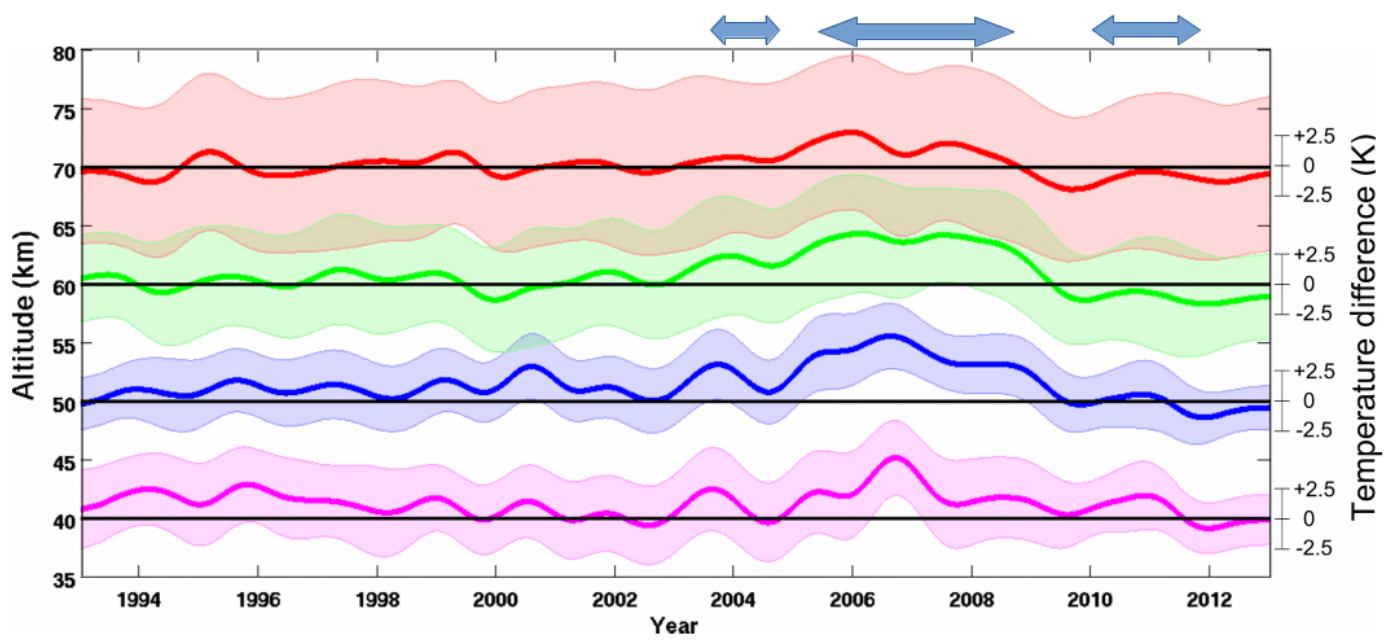

Figure 14. Average temperature differences between $\mathrm{LTA}$ and $\mathrm{LiO}_{3} \mathrm{~S}$ OHP lidars for a 20-year period between 1993 and 2013 at four altitude levels: $65-75 \mathrm{~km}$ (red), 55-65 km (green), 45-55 km (blue), and 35-45 km (magenta). Shaded uncertainties are shown at $1 \sigma$ for clarity, and the black lines are zero temperature difference displaced to 40,50,60, and $70 \mathrm{~km}$. All measurements, including periods of lidar misalignment, are included in this plot. The apparent anomalies (blue arrows) occur only during times where the lidars were often misaligned, as indicated in Fig. 13.

extremely challenging and will not be accomplished in this work.

Given that the primary interest of this work is the upper middle atmosphere (nominally above $50 \mathrm{~km}$ ), we will focus on the upper portions of Fig. 15 where the two lidars are in statistically perfect agreement. To our knowledge, this is the first-ever long-term study of the temperatures produced by co-located temperature lidars operating at 532 and $355 \mathrm{~nm}$. The excellent agreement between these two independent measurements gives us confidence that (a) there is no vertical misalignment between the lidars, (b) there are no unaccounted-for optical transmission effects which influence our temperatures, (c) the lidar measurements are reasonable and reproducible, and (d) we can now proceed with some confidence that our ground-based lidar measurements can be useful as a calibration source for the space-based satellite measurements. 


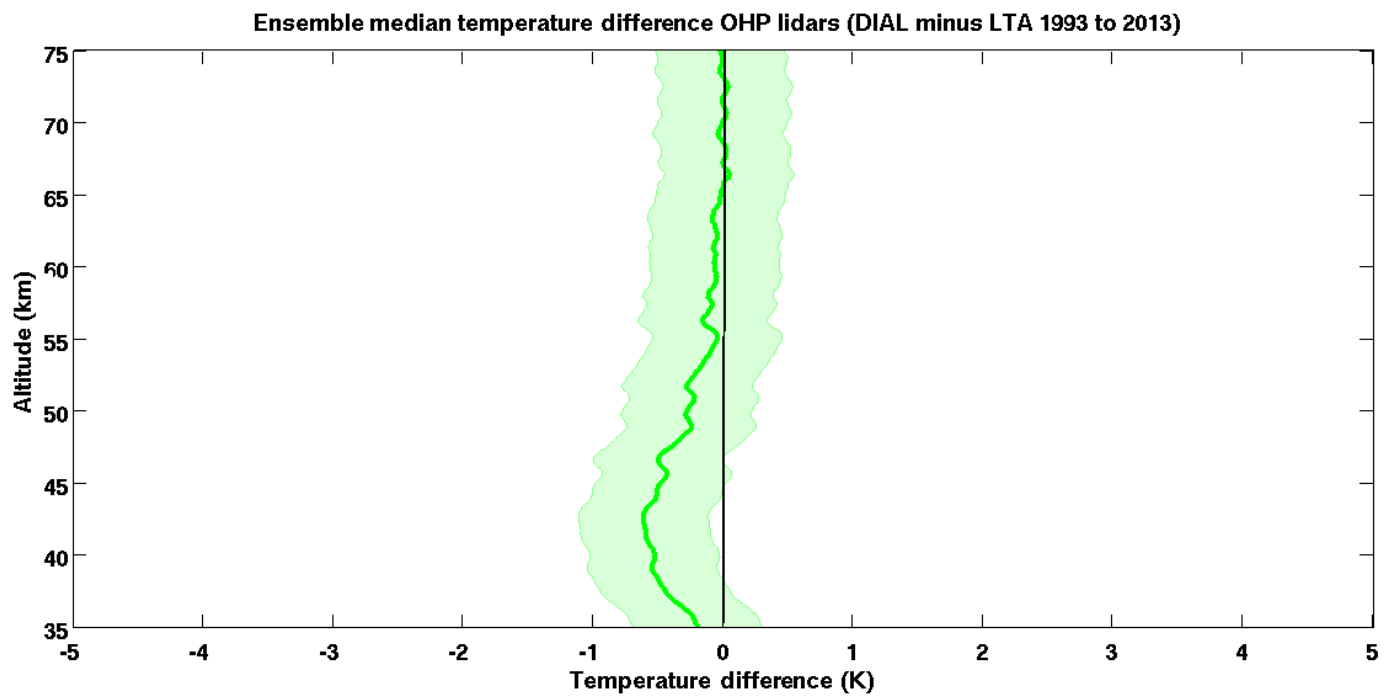

Figure 15. Ensemble of median temperature differences between LTA and $\mathrm{LiO}_{3} \mathrm{~S}$ based on temperature measurements between 1993 and 2013. Shaded error is the $2 \sigma$ distribution about the ensemble.

\section{Summary and discussion}

\subsection{Changes to lidar temperature algorithm}

In this work we have attempted to minimize the systematic temperature bias at the top-of-the-atmosphere lidar temperature retrieval which has been noted previously by several studies cited in the Introduction. We have done this by clearly and carefully outlining a rigorous and complete algorithm for the calculation of lidar temperatures in the UMLT. We have presented techniques for the detection of signal contamination, the selection of the best data for inclusion in the calculation, and criteria for where to initialize the inversion when assuming an a priori pressure at the top of the atmosphere, and we have demonstrated the benefit of photomultiplier cooling and narrow-bandpass filters to reduce lidar backgrounds.

After applying our techniques, we have seen a systematic cooling of the high-altitude lidar temperatures which brings them into better agreement with the temperatures measured by both MLS and SABER (Fig. 11). It is also important to note that the large variance associated with these ensemble differences can partially be attributed to the lack of control exerted on the error contribution from the choice of a priori initial pressure for lidar data and a priori contribution and non-LTE effects for satellite data. Part of the difference may also be due to altitude offsets and coarse vertical resolution.

Having applied these new data filtering techniques, we have produced an improved lidar temperature data set which is exploited in the companion paper (Wing et al., 2018) in an effort to validate satellite temperatures.

\subsection{OHP lidar 20-year comparison}

We have conducted the first-ever decadal temperature intercomparison between a co-located $532 \mathrm{~nm}$ Rayleigh lidar and an ozone DIAL system calculating temperatures from a $355 \mathrm{~nm}$ line. We have shown the following:

1. Rayleigh lidar temperatures calculated from ozone DIAL non-absorbing $355 \mathrm{~nm}$ line are statistically equal to temperatures from a traditional $532 \mathrm{~nm}$ Rayleigh temperature lidar over a large altitude range. This finding is of particular interest for the NDACC lidar temperature database as temperatures from ozone lidars may also be available for validation and inclusion.

2. Further theoretical work must be done on algorithms for melding data from high- and low-gain photoncounting channels. The current techniques produce statistically identical nightly temperature profiles; however, a $-0.6 \mathrm{~K}$ bias near $40 \mathrm{~km}$ becomes apparent when multiple years of data are compared. It is doubtful that current data processing techniques can be easily adapted to address this problem. However, an iterative, costminimizing Bayesian approach such as the one proposed by Sica and Haefele (2015) would be able to produce a single melded temperature profile with the accompanying averaging kernels and an estimate of the error due to the photon count melding. As a lidar development note, Fig. 13 demonstrates the need to move towards the use of automated nightly alignment of lidar system optics. Manual alignment by operators appears to lack consistency over the time frame of multiple decades. 
3. The two independent lidars show no evidence of significant instrument drift over a 20 -year period. This means that ground-based lidars are the ideal choice of instrument for detecting small calibration drifts in satellite remote measurements over long timescales. We rely on this finding to justify the use of lidars as a reference data set for satellite validation in the companion paper (Wing et al., 2018).

4. There is no evidence of a relative vertical offset between the two independently calibrated lidar systems, which would be seen as an "S"-shaped temperature bias in Fig. 15 due to the sign change in temperature vertical gradient at the stratopause (Leblanc et al., 1998a). Based on personal communication, the recent JulyAugust 2017 and March 2018 NDACC ozone validation campaign at OHP (LAVANDE) revealed no vertical shifts between either OHP lidar and the NASA STROZ mobile validation lidar (McGee et al., 1995).

Data availability. The data used in this paper were obtained as part of the Network for the Detection of Atmospheric Composition Change (NDACC) and are publicly available (see http://www.ndsc. ncep.noaa.gov/data/, CPC Team, 2018) as well as from the SABER (see http://saber.gats-inc.com/data.php, SABER, 2018) and MLS (see https://mls.jpl.nasa.gov, Microwave Limb Sounder, 2018) data centres for public access.

Author contributions. RW conceived of the presented idea, wrote the required codes, re-processed the data, performed the computations, and wrote the manuscript. AH and PK supervised the work, provided access to LTA data, and offered scientific insight. SGB provided access to LiO3S data and offered scientific insight. SK helped supervise the work and offered scientific insight. EMM edited the drafts, provided key criticisms to improve the work, helped refine the ideas in the manuscript, and provided scientific insight. JFM provided the technical specifications for the design of the lidars. ED provided the original NDACC lidar temperatures and provided the technical specifications for data processing. All authors discussed the results and contributed to the final manuscript.

Competing interests. The authors declare that they have no conflict of interest.

Acknowledgements. This work is supported by the Atmospheric dynamics Research InfraStructure in Europe Project (ARISE 2), which is funded by the European Union's Horizon 2020 research and innovation programme under grant agreement no. 653980. French NDACC activities are supported by Institut National des Sciences de l'Univers/Centre National de la Recherche Scientifique (INSU/CNRS), Université de Versailles Saint-Quentin-en-Yvelines (UVSQ), and Centre National d'Études Spatiales (CNES). The authors would also like to thank Caitlyn Wing for graphics support and the technicians at La Station Géophysique Gérard Mégie at
OHP.

Edited by: Markus Rapp

Reviewed by: three anonymous referees

\section{References}

Alpers, M., Eixmann, R., Fricke-Begemann, C., Gerding, M., and Höffner, J.: Temperature lidar measurements from 1 to $105 \mathrm{~km}$ altitude using resonance, Rayleigh, and Rotational Raman scattering, Atmos. Chem. Phys., 4, 793-800, https://doi.org/10.5194/acp-4-793-2004, 2004.

Apruzese, J. P., Strobel, D. F., and Schoeberl, M. R.: Parameterization of IR cooling in a Middle Atmosphere Dynamics Model: 2. Non-LTE radiative transfer and the globally averaged temperature of the mesosphere and lower thermosphere, J. Geophys. Res.-Atmos., 89, 4917-4926, https://doi.org/10.1029/JD089iD03p04917, 1984.

Argall, P. S.: Upper altitude limit for Rayleigh lidar, Ann. Geophys., 25, 19-25, https://doi.org/10.5194/angeo-25-19-2007, 2007.

CPC Team: NDACC Data, available at: http://www.ndsc.ncep.noaa. gov/data/, last access: 8 October 2018.

Donovan, D. P., Whiteway, J. A., and Carswell, A. I.: Correction for nonlinear photon-counting effects in lidar systems, Appl. Opt., 32, 6742-6753, https://doi.org/10.1364/AO.32.006742, 1993.

Dou, X., Li, T., Xu, J., Liu, H.-L., Xue, X., Wang, S., Leblanc, T., McDermid, I. S., Hauchecorne, A., Keckhut, P., Bencherif, H., Heinselman, C., Steinbrecht, W., Mlynczak, M. G., and Russell, J. M.: Seasonal oscillations of middle atmosphere temperature observed by Rayleigh lidars and their comparisons with TIMED/SABER observations, J. Geophys. Res.-Atmos., 114, D20103, https://doi.org/10.1029/2008JD011654, 2009.

García-Comas, M., Funke, B., Gardini, A., López-Puertas, M., Jurado-Navarro, A., von Clarmann, T., Stiller, G., Kiefer, M., Boone, C. D., Leblanc, T., Marshall, B. T., Schwartz, M. J., and Sheese, P. E.: MIPAS temperature from the stratosphere to the lower thermosphere: Comparison of vM21 with ACE-FTS, MLS, OSIRIS, SABER, SOFIE and lidar measurements, Atmos. Meas. Tech., 7, 3633-3651, https://doi.org/10.5194/amt-7-36332014, 2014.

Godin-Beekmann, S., Porteneuve, J., and Garnier, A.: Systematic DIAL lidar monitoring of the stratospheric ozone vertical distribution at Observatoire de Haute-Provence $\left(43.92^{\circ} \mathrm{N}, 5.71^{\circ} \mathrm{E}\right)$, J. Environ. Monitor., 5, 57-67, https://doi.org/10.1039/B205880D, 2003.

Gross, M. R., McGee, T. J., Ferrare, R. A., Singh, U. N., and Kimvilakani, P.: Temperature measurements made with a combined Rayleigh-Mie and Raman lidar, Appl. Opt., 36, 59875995, https://doi.org/10.1364/AO.36.005987, 1997.

Hauchecorne, A. and Chanin, M.-L.: Density and temperature profiles obtained by lidar between 35 and $70 \mathrm{~km}$, Geophys. Res. Lett., 7, 565-568, https://doi.org/10.1029/GL007i008p00565, 1980.

Keckhut, P., Hauchecorne, A., and Chanin, M.: A critical review of the database acquired for the long-term surveillance of the middle atmosphere by the French Rayleigh lidars, J. Atmos. Ocean. Tech., 10, 850-867, https://doi.org/10.1175/15200426(1993)010<0850:ACROTD>2.0.CO;2, 1993. 
Keckhut, P., McDermid, S., Swart, D., McGee, T., GodinBeekmann, S., Adriani, A., Barnes, J., Baray, J.-L., Bencherif, H., Claude, H., di Sarra, A. G., Fiocco, G., Hansen, G., Hauchecorne, A., Leblanc, T., Lee, C. H., Pal, S., Megie, G., Nakane, H., Neuber, R., Steinbrecht, W., and Thayer, J.: Review of ozone and temperature lidar validations performed within the framework of the Network for the Detection of Stratospheric Change, J. Environ. Monit., 6, 721-733, https://doi.org/10.1039/B404256E, 2004.

Khanna, J., Sica, R. J., and McElroy, C. T.: Atmospheric temperature retrievals from lidar measurements using techniques of non-linear mathematical inversion, AGU Fall Meeting Abstracts, 2011.

Khanna, J., Bandoro, J., Sica, R. J., and McElroy, C. T.: New technique for retrieval of atmospheric temperature profiles from Rayleigh-scatter lidar measurements using nonlinear inversion, Appl. Opt., 51, 7945-7952, https://doi.org/10.1364/AO.51.007945, 2012.

Khaykin, S. M., Godin-Beekmann, S., Keckhut, P., Hauchecorne, A., Jumelet, J., Vernier, J.-P., Bourassa, A., Degenstein, D. A., Rieger, L. A., Bingen, C., Vanhellemont, F., Robert, C., DeLand, M., and Bhartia, P. K.: Variability and evolution of the midlatitude stratospheric aerosol budget from 22 years of ground-based lidar and satellite observations, Atmos. Chem. Phys., 17, 18291845, https://doi.org/10.5194/acp-17-1829-2017, 2017.

Kumar, V. S., Rao, P. B., and Krishnaiah, M.: Lidar measurements of stratosphere' mesosphere thermal structure at a low latitude: Comparison with satellite data and models, J. Geophys. Res.Atmos., 108, D11, https://doi.org/10.1029/2002JD003029, 2003.

Leblanc, T., McDermid, I. S., Hauchecorne, A., and Keckhut, P.: Evaluation of optimization of lidar temperature analysis algorithms using simulated data, J. Geophys. Res.-Atmos., 103, 6177-6187, https://doi.org/10.1029/97JD03494, 1998a.

Leblanc, T., McDermid, I. S., Keckhut, P., Hauchecorne, A., She, C. Y., and Krueger, D. A.: Temperature climatology of the middle atmosphere from long-term lidar measurements at middle and low latitudes, J. Geophys. Res.-Atmos., 103, 17191-17204, https://doi.org/10.1029/98JD01347, 1998b.

Mann, H. B. and Whitney, D. R.: On a Test of Whether one of Two Random Variables is Stochastically Larger than the Other, Ann. Math. Statist., 18, 50-60, https://doi.org/10.1214/aoms/1177730491, 1947.

McGee, T. J., Ferrare, R. A., Whiteman, D. N., Butler, J. J., Burris, J. F., and Owens, M. A.: Lidar measurements of stratospheric ozone during the STOIC campaign, J. Geophys. Res.-Atmos., 100, 9255-9262, https://doi.org/10.1029/94JD02390, 1995.

Microwave Limb Sounder: Microwave Limb Sounder Home, available at: https://mls.jpl.nasa.gov/, last access: 25 April 2018.

Picone, J. M., Hedin, A. E., Drob, D. P., and Aikin, A. C.: NRLMSISE 00 empirical model of the atmosphere: Statistical comparisons and scientific issues, J. Geophys. Res.-Space, 107, SIA 151-SIA 15-16, https://doi.org/10.1029/2002JA009430, 2002.
Remsberg, E. E., Marshall, B. T., Garcia-Comas, M., Krueger, D., Lingenfelser, G. S., Martin-Torres, J., Mlynczak, M. G., Russell, J. M., Smith, A. K., Zhao, Y., Brown, C., Gordley, L. L., LopezGonzalez, M. J., Lopez-Puertas, M., She, C.-Y., Taylor, M. J., and Thompson, R. E.: Assessment of the quality of the Version 1.07 temperature-versus-pressure profiles of the middle atmosphere from TIMED/SABER, J. Geophys. Res.-Atmos., 113, D17101, https://doi.org/10.1029/2008JD010013, 2008.

SABER: Sounding of the Atmosphere using Broadband Emission RadiometrySA, available at: http://saber.gats-inc.com/data.php, last access: 25 April 2018.

Sica, R. and Haefele, A.: Retrieval of temperature from a multiple-channel Rayleigh-scatter lidar using an optimal estimation method, Appl. Opt., 54, 1872-1889, https://doi.org/10.1364/AO.54.001872, 2015.

Singh, U. N., Keckhut, P., McGee, T. J., Gross, M. R., Hauchecorne, A., Fishbein, E. F., Waters, J. W., Gille, J. C., Roche, A. E., and Russell, J. M.: Stratospheric temperature measurements by two collocated NDSC lidars during UARS validation campaign, J. Geophys. Res.-Atmos., 101, 10287-10297, https://doi.org/10.1029/96JD00516, 1996.

Sivakumar, V., Vishnu Prasanth, P., Kishore, P., Bencherif, H., and Keckhut, P.: Rayleigh LIDAR and satellite (HALOE, SABER, CHAMP and COSMIC) measurements of stratospheremesosphere temperature over a southern sub-tropical site, Reunion $\left(20.8^{\circ} \mathrm{S} ; 55.5^{\circ} \mathrm{E}\right)$ : climatology and comparison study, Ann. Geophys., 29, 649-662, https://doi.org/10.5194/angeo-29649-2011, 2011.

Taori, A., Jayaraman, A., Raghunath, K., and Kamalakar, V.: A new method to derive middle atmospheric temperature profiles using a combination of Rayleigh lidar and $\mathrm{O}_{2}$ airglow temperatures measurements, Ann. Geophys., 30, 27-32, https://doi.org/10.5194/angeo-30-27-2012, 2012a.

Taori, A., Kamalakar, V., Raghunath, K., Rao, S., and Russell, J.: Simultaneous Rayleigh lidar and airglow measurements of middle atmospheric waves over low latitudes in India, J. Atmos. Sol.-Terr. Phy., 78-79, 62-69, https://doi.org/10.1016/j.jastp.2011.06.012, 2012b.

Tukey, J. W.: Comparing Individual Means in the Analysis of Variance, Biometrics, 5, 99-114, 1949.

Wing, R., Hauchecorne, A., Keckhut, P., Godin-Beekmann, S., Khaykin, S., and McCullough, E. M.: Lidar temperature series in the middle atmosphere as a reference data set. Part B: Assessment of temperature observations from MLS/Aura and SABER/TIMED satellites, Atmos. Meas. Tech. Discuss., https://doi.org/10.5194/amt-2018-139, in review, 2018.

Yue, C., Yang, G., Wang, J., Guan, S., Du, L., Cheng, X., and Yang, Y.: Lidar observations of the middle atmospheric thermal structure over north China and comparisons with TIMED/SABER, J. Atmos. Sol.-Terr. Phy., 120, 80-87, https://doi.org/10.1016/j.jastp.2014.08.017, 2014. 